Article

\title{
Performance of the Remotely-Derived Products in Monitoring Gross Primary Production across Arid and Semi-Arid Ecosystems in Northwest China
}

\author{
Qing Gu ${ }^{1,2}$, Hui Zheng ${ }^{3}$, Li Yao ${ }^{1,3, *}$, Min Wang ${ }^{1}$, Mingguo Ma ${ }^{1}\left(\mathbb{D}\right.$, Xufeng Wang ${ }^{4}(\mathbb{D}$ \\ and Xuguang Tang ${ }^{1,2}$ \\ 1 Chongqing Engineering Research Center for Remote Sensing Big Data Application, \\ School of Geographical Sciences, Southwest University, Chongqing 400715, China; \\ qingu710@email.swu.edu.cn (Q.G.); michelle0726@email.swu.edu.cn (M.W.); \\ mmg@swu.edu.cn (M.M.); xgtang@swu.edu.cn (X.T.) \\ 2 Key Laboratory of Watershed Geographic Sciences, Nanjing Institute of Geography and Limnology, \\ Chinese Academy of Sciences, Nanjing 210008, China \\ 3 Key Laboratory of Geospatial Technology for the Middle and Lower Yellow River Regions, \\ Henan University, Kaifeng 475004, China; 10130103@vip.henu.edu.cn \\ 4 Northwest Institute of Eco-Environment and Resources, Chinese Academy of Sciences, \\ Lanzhou 730000, China; wangxufeng@lzb.ac.cn \\ * Correspondence: yao66625@swu.edu.cn; Tel.: +86-23-6825-3911
}

Received: 3 August 2020; Accepted: 20 August 2020; Published: 22 August 2020

check for updates

\begin{abstract}
As an important component to quantify the carbon budget, accurate evaluation of terrestrial gross primary production (GPP) is crucial for large-scale applications, especially in dryland ecosystems. Based on the in situ data from six flux sites in northwestern China from 2014 to 2016, this study compares seasonal and interannual dynamics of carbon fluxes between these arid and semi-arid ecosystems and the atmosphere. Meanwhile, the reliability of multiple remotely-derived GPP products in representative drylands was examined, including the Breathing Earth System Simulator (BESS), the Moderate Resolution Imaging Spectroradiometer (MODIS) and data derived from the OCO-2 solar-induced chlorophyll fluorescence (GOSIF). The results indicated that the carbon fluxes had clear seasonal patterns, with all ecosystems functioning as carbon sinks. The maize cropland had the highest GPP with $1183 \mathrm{~g} \mathrm{C} \mathrm{m}^{-2} \mathrm{y}^{-1}$. Although the net ecosystem carbon exchange (NEE) in the Tamarix spp. ecosystem was the smallest among these flux sites, it reached $208 \mathrm{~g} \mathrm{C} \mathrm{m}^{-2} \mathrm{y}^{-1}$. Furthermore, distinct advantages of GOSIF GPP (with $\mathrm{R}^{2}=0.85-0.98$, and RMSE $=0.87-2.66 \mathrm{~g} \mathrm{C} \mathrm{m}^{-2} \mathrm{~d}^{-1}$ ) were found with good performance. However, large underestimations in three GPP products existed during the growing seasons, except in grassland ecosystems. The main reasons can be ascribed to the uncertainties in the key model parameters, including the underestimated light use efficiency of the MODIS GPP, the same coarse land cover product for the BESS and MODIS GPP, the coarse gridded meteorological data, and distribution of $\mathrm{C}_{3}$ and $\mathrm{C}_{4}$ plants. Therefore, it still requires more work to accurately quantify the GPP across these dryland ecosystems.
\end{abstract}

Keywords: carbon management; eddy covariance; BESS GPP; MODIS GPP; GOSIF GPP

\section{Introduction}

Climate change and climate extremes always exert a substantial impact on the biosphere, but the response, as well as the underlying mechanism, vary among different vegetation types [1]. Especially under the context of global warming, the arid and semi-arid (ASA) regions are projected to expand further in the coming decades [2,3]. Koutroulis [4] found that the dryland had enlarged by $4-8 \%$ 
over the past century, and covered almost $47 \%$ of the Earth's surface, among which the ASA ecosystems accounted for a large part (about $64 \%$ ) and were indispensable parts of the global carbon balance. Furthermore, drylands are vulnerable to environmental changes, resulting in land degradation called desertification [5]. Zika and Erb [6] found that around 2\% of the global gross primary productivity (GPP) was lost each year due to climate and human-induced dryland degradation. Research has found that more than half of the exceptionally large land carbon sink was caused by semi-arid vegetation in Australia [7]. Biederman [8] also found that the carbon budgets at diverse vegetation types differed widely. Although many methods have been developed, for example, remote sensing inversion [9] and process-based simulation $[8,10]$, it remains difficult to accurately quantify the carbon fluxes across ASA ecosystems.

Recently, the eddy covariance (EC) technique has been of increasing importance to get the net ecosystem carbon exchange (NEE) between the ecosystem and the atmosphere because of its directness and continuity [11,12]. As a result, evaluations of the differences in carbon sequestration among diverse ecosystems on the Earth as well as the underlying mechanisms are emerging $[13,14]$. Meanwhile, the value of GPP can be indirectly calculated based on the continuous observation recorded [15]. However, it is difficult to directly upscale the site-level observations to a large region.

Semi-empirical approaches [16] and process-based models [17] play significant roles in generating space-time continuous GPP datasets. The Moderate Resolution Imaging Spectroradiometer (MODIS) GPP used the light use efficiency (LUE) models, based on Monteith's production efficiency concept [18]. As the earliest and most commonly used GPP product, the MODIS GPP has been updated to version 6 with a finer spatial resolution of $500 \mathrm{~m}$. The Breathing Earth System Simulator (BESS) is a succinct process-based model for continuously monitoring carbon and water fluxes [17]. BESS-derived GPP coupled photosynthesis and transpiration [19], atmospheric and land processes [20]. Furthermore, it used a two-leaf model [21] and considered foliar clumping effects [22]. Global BESS GPP datasets were generated by integrating remote sensing data with process-based models. In recent years, two global GPP products from the MODIS and BESS have become widely used. Compared with the MODIS GPP, the BESS GPP allows a thorough understanding of the potential interaction mechanisms and synergetic responses to environmental change [23]. In addition, satellite-based measurements of solar-induced chlorophyll fluorescence (SIF) have provided a new opportunity for studying the GPP at regional to global scales. Based on the global SIF product measured by the Orbiting Carbon Observatory-2 (OCO-2), Li and Xiao [24] mapped the GOSIF GPP globally at a $0.05^{\circ}$ spatial resolution and eight-day time step for the period from 2000 to 2018.

The accuracy and reliability of these products are the keys to large-scale applications. To meet the actual requirements, the performance of these products needs to be evaluated in advance across diverse ecosystems [25,26]. Based on MODIS GPP datasets, Zhang [27] analyzed the space-time distribution of carbon sinks at the three-river headwaters region, but only focused on a single vegetation ecosystem. Although Wang [28] improved the estimation of the MODIS GPP by a model-data fusion approach in ASA ecosystems, the model's performance in the desert steppe and forest ecosystem and the difference from other GPP products is unclear. Jiang and Ryu [29] evaluated the performance of the BESS products on a global scale and found that the BESS GPP generally performed better than the MODIS GPP. Li and Xiao [24] also showed that the GOSIF GPP performance highly correlated with the flux tower-based GPP from global 91 open-access sites. However, it is not confirmed whether the performance of the BESS GPP and GOSIF GPP is still confident in the ecologically-fragile ASA regions, and few people have systematically focused on the performance of the BESS, MODIS, and GOSIF GPP in arid and semi-arid regions.

In this study, six typical flux sites were used including cropland, grassland, wetland, and woodland across northwestern China, and aimed to: (i) analyze the distribution of carbon fluxes on seasonal and interannual time scales; (ii) investigate the reliability of the BESS, MODIS, and GOSIF GPP products; and (iii) analyze the uncertainty of these remotely-derived products over different ecosystems in 
ASA regions. All analyses will provide scientific supports for regional carbon management and decision-making for climate change mitigation and adaptation.

\section{Materials and Methods}

\subsection{Study Area and Flux Sites}

In this research, a typical ASA area of northwest China with of about 143,000 $\mathrm{km}^{2}$, the inland Heihe river basin, is selected as the main research region (Figure 1). Distinctive cold and arid landscapes are widely spread around the whole Heihe river basin [30,31]. In May 2012, the Heihe Watershed Allied Telemetry Experimental Research (HiWATER) was carried out in northwest China [32]. In August of the next year, a hydrometeorological observation network was fully built and put into operation as part of ChinaFlux. A string of flux towers on various vegetation types was installed to monitor the ecosystem scale $\mathrm{CO}_{2}$ and $\mathrm{H}_{2} \mathrm{O}$ exchanges and these provide basic data for the study. A total of six flux sites were used in this research, namely [33], the Daman superstation (S_Dm), the A'rou superstation (S_Ar), the Zhangye wetland station (S_Zy), the Dashalong station (S_Dsl), the Sidaoqiao superstation (S_Sdq), and the Hunhelin station (S_Hhl). These flux sites cover the main types of ASA ecosystems, including two grasslands, one wetland, two woodlands, and one cultivated land.

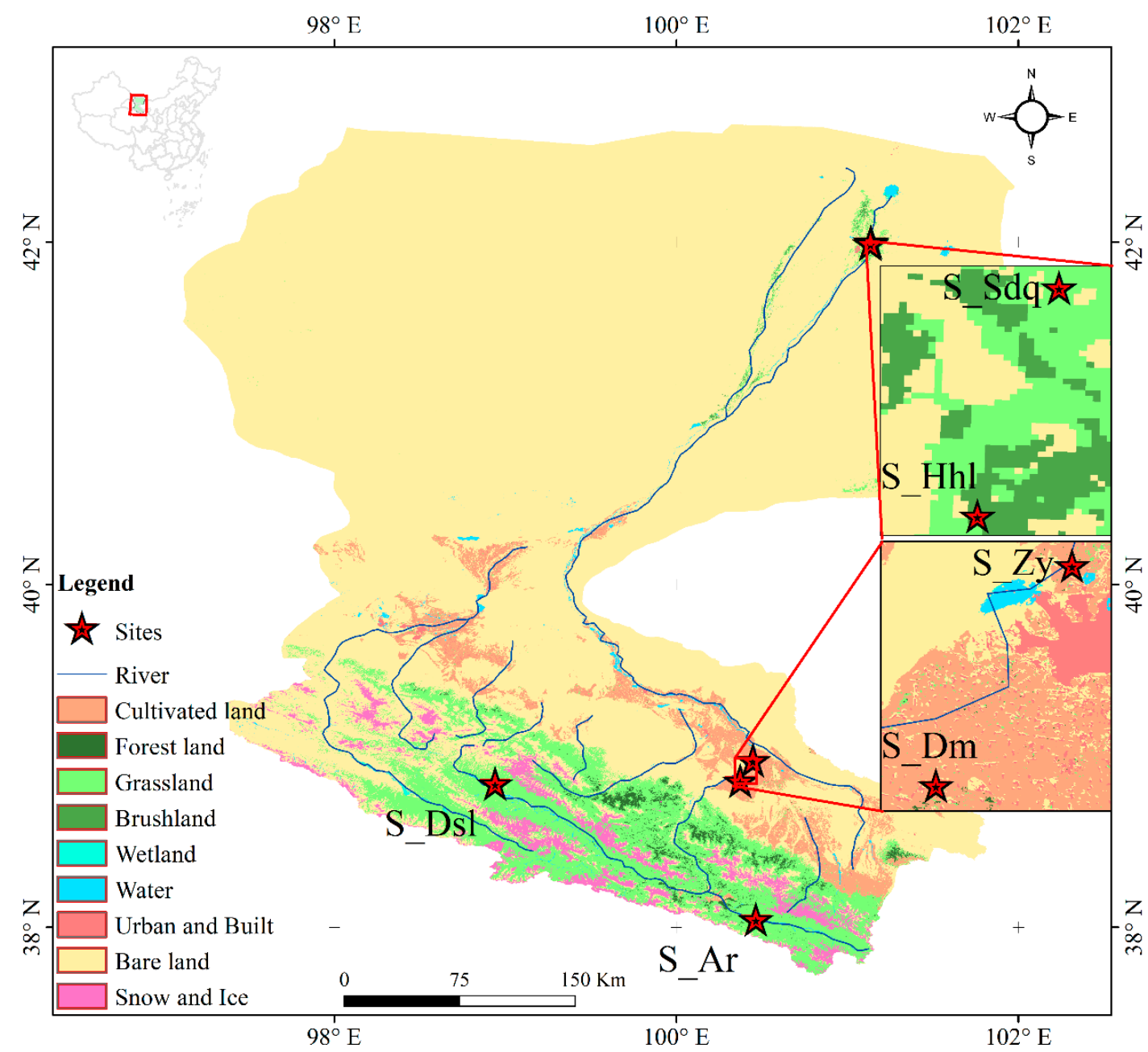

Figure 1. Distribution of the six flux sites in northwestern China. The land cover classification data are from land use and land cover data of the Heihe River Basin in 2000 (http://www.heihedata.org/data/).

The S_Dm site and the S_Zy site are located in the Daman and Yingke irrigated areas near Zhangye city Gansu province, respectively. They are also in the midstream of the Heihe river (artificial oasis 
experimental area) having a continental arid climate [32]. The S_Zy site is situated on a wetland with a reed surface in the Zhangye National Wetland Park. The S_Ar and the S_Dsl sites are part of the upstream cold region experimental area. The former is in a valley with an east-west direction and a maximum width of $3 \mathrm{~km}$ [15]. The latter is covered with snow most of the time [34]. The S_Sdq and the S_Hhl sites are located on the natural oasis experimental area in the downstream. More information can be found in Table 1 and Figure 1.

Table 1. Descriptions of the flux sites used in this study.

\begin{tabular}{cccccccc}
\hline Site Name & Location & $\begin{array}{c}\text { Altitude } \\
(\mathbf{m})\end{array}$ & $\begin{array}{c}\text { Observation } \\
\text { Height }(\mathbf{m})\end{array}$ & Vegetation Type & $\begin{array}{c}\text { Mean } \\
\text { Temperature }\left({ }^{\circ} \mathbf{C}\right)\end{array}$ & $\begin{array}{c}\text { Precipitation } \\
(\mathbf{m m})\end{array}$ & Available Years \\
\hline $\begin{array}{c}\text { A'rou } \\
\text { (S_Ar) }\end{array}$ & $\begin{array}{c}100.4643^{\circ} \mathrm{E} \\
38.0473^{\circ} \mathrm{N}\end{array}$ & 3033 & 3.5 & Alpine meadow & $0.03 \pm 0.62$ & $460 \pm 63$ & $2014.01-2016.12$ \\
$\begin{array}{c}\text { Daman } \\
\text { (S_Dm) }\end{array}$ & $\begin{array}{c}100.3722^{\circ} \mathrm{E} \\
38.8555^{\circ} \mathrm{N}\end{array}$ & 1556 & 4.5 & Maize cropland & $6.92 \pm 0.16$ & $129 \pm 26$ & $2014.01-2016.12$ \\
$\begin{array}{c}\text { Dashalong } \\
\text { (S_Dsl) }\end{array}$ & $\begin{array}{c}98.9406^{\circ} \mathrm{E} \\
38.8399^{\circ} \mathrm{N}\end{array}$ & 3739 & 4.5 & Swamp meadow & $-3.96 \pm 0.47$ & $341 \pm 41$ & $2014.01-2016.12$ \\
$\begin{array}{c}\text { Hunhelin } \\
\text { (S_Hhl) }\end{array}$ & $\begin{array}{c}101.1335^{\circ} \mathrm{E} \\
41.9903^{\circ} \mathrm{N}\end{array}$ & 874 & 22 & $\begin{array}{c}\text { Populus euphratica } \\
\text { and Tamarix }\end{array}$ & $10.38 \pm 0.14$ & $34 \pm 17$ & $2014.01-2016.12$ \\
$\begin{array}{c}\text { Sidaoqiao } \\
\text { (S_Sdq) }\end{array}$ & $\begin{array}{c}101.1374^{\circ} \mathrm{E} \\
42.0012^{\circ} \mathrm{N}\end{array}$ & 873 & 8 & Tamarix & $9.36 \pm 0.11$ & $33 \pm 9$ & $2014.01-2016.12$ \\
$\begin{array}{c}\text { Zhangye } \\
\text { (S_Zy) }\end{array}$ & $\begin{array}{c}100.4464^{\circ} \mathrm{E} \\
38.9751^{\circ} \mathrm{N}\end{array}$ & 1460 & 5.2 & Wetland & $9.45 \pm 0.34$ & $95 \pm 24$ & $2014.01-2016.12$ \\
\hline
\end{tabular}

The mean temperature represents the average daily temperature from 2014 to 2016 and precipitation represents cumulative average annual precipitation from 2014 to 2016 for each flux site. The standard deviations of mean temperature and precipitation are also attached.

\subsection{Flux Data Acquisition and Processing}

Each flux tower site has two systems including an EC and an automatic weather station (AWS) system, to obtain the energy fluxes and meteorological data. A three-dimensional sonic anemometer (CSAT3, Campbell Scientific, Logan, UT, USA) and a Li7500A open path $\mathrm{CO}_{2} / \mathrm{H}_{2} \mathrm{O}$ gas analyzer (LI-COR Inc., NE, USA) form an EC system to measure ecosystem scale $\mathrm{CO}_{2}$ and $\mathrm{H}_{2} \mathrm{O}$ fluxes. The sampling rate was set to $10 \mathrm{~Hz}$. Before releasing data to the public, the $10 \mathrm{~Hz}$ data was processed into a half-hour flux dataset by the Edire post-processing software (University of Edinburgh, Edinburgh, $\mathrm{UK}$ ). The spike detection, lag correction of $\mathrm{H}_{2} \mathrm{O} / \mathrm{CO}_{2}$, sonic virtual temperature correction, coordinate rotation, Webb-Pearman-Leuning correction (WPL) [35], and frequency response correction were included in the procedures. In addition, sensor-faults, rain, and other bad weather can easily cause data loss or low quality. Therefore, data with poor quality was checked and excluded from the half-hour data [36]. The AWS system measures the relevant weather conditions including air temperature (Ta) $\left({ }^{\circ} \mathrm{C}\right)$, precipitation $(\mathrm{mm})$, etc. [37]. The data of the AWS system were recorded every ten minutes.

In this study, three-year flux data and meteorological data of these typical sites were obtained from the Environmental and Ecological Science Data Center of West China (http://westdc.westgis.ac.cn). Then, preprocessing such as outlier elimination was carried out. Gap-filling by a standardized algorithm and flux partitioning by the nighttime-based method were carried out with the R package by the Max Planck Institute for Biogeochemistry (https:/www.bgc-jena.mpg.de/bgi/index.php/Services/ REddyProcWeb). Flux partition was used to partition NEE into the GPP and ecosystem respiration $\left(R_{e}\right)$. In particular, the latent heat flux and carbon dioxide flux data were missing from 1st May 2016 to 23rd August 2016 because of a malfunction of the Li7500 at the S_Sdq site and we gap-filled this part with multi-year mean imputation. Finally, we integrated these half-hour data into the daily time scale and then got the average of each eight-day period to compare with the BESS, MODIS, and GOSIF products.

\subsection{Remote Sensing Products and Processing}

The BESS is designed to continuously measure global carbon and water fluxes [29] and provides the global $1 \mathrm{~km}$ resolution GPP product with an interval of eight days during the period from 2000 to 2015. In the BESS-derived GPP, radiation, photosynthetic active radiation, and near-infrared radiation 
at the top of the canopy were calculated by an atmospheric radiative transfer model, and then these parameters, absorbed by the sunlit and shade leaves, were gained by a two-leaf canopy radiative transfer model. Furthermore, it used the biochemical photosynthesis models for $C_{3}$ and $C_{4}$ plants, and parameterized maximum carboxylation rate based on plant functional type, climatic zones, and the season. The BESS products used seven MODIS atmospheric and land products, four other satellites, four reanalyses, and three auxiliary datasets.

We used the MODIS GPP version 6 (MOD17A2H) obtained from the Terra platform, with $500 \mathrm{~m}$ spatial resolution [36], which is produced using the LUE model as follows:

$$
\mathrm{GPP}=\mathrm{LUE}_{\max } \times \mathrm{f}\left(\mathrm{T}_{\mathrm{MIN}}\right) \times \mathrm{f}(\mathrm{VPD}) \times \mathrm{SWRad} \times 0.45 \times \text { FPAR }
$$

where LUE $_{\max }$ is the maximum value of light use efficiency, while SWRad denotes incident shortwave radiation. $T_{\min }$ is the daily minimum temperature, VPD is the daylight average vapor pressure deficit, and FPAR is the fractional photo-synthetically active radiation absorbed by the canopy. The algorithm logic and model parameters can also be found in the MOD17 user guide [38]. The model assumed that the GPP is proportional to plant absorption and effective radiation under ideal conditions [39]. A set of biome-specific radiation-use efficiency parameters was acquired from the updated Biome Property Look Up Tables. The product also used a new version of the daily Global Modeling and Assimilation Office (GMAO) meteorological data [39]. The product used in this study was downloaded from NASA's Earth Observing System Data and Information System (https://search.earthdata.nasa.gov). We re-sampled it to $1 \mathrm{~km}$ pixel size before being extracted based on site locations.

The GOSIF GPP product was developed by Li and Xiao [24], with a $0.05^{\circ}$ spatial resolution and an eight-day time step for the period from 2000 to 2018. The GOSIF GPP product benefited from the breakthrough of two key matters, the relationship between SIF and GPP, and SIF data with high spatial and temporal resolutions. For the relationship between SIF and GPP, Li and Xiao [40] found a nearly universal SIF-GPP relationship. The SIF data used the global OCO-2 SIF data set (GOSIF) with a $0.05^{\circ}$ spatial resolution and an eight-day time step. The GOSIF product was developed by Li and Xiao [41], based on discrete OCO-2 SIF soundings, MODIS data, and MERRA-2 meteorological data. In this study, the BESS, MODIS, and GOSIF GPP data from 2014-2015 were selected uniformly, and we extracted the value based on the geographical location of each flux site for completing the performance.

\subsection{Statistical Analyses}

To quantify the relationships between two GPP products and EC-based data in major ecosystems, we used two statistical criteria: the root-mean-square error (RMSE) and $R^{2}$. The equations of RMSE and $\mathrm{R}^{2}$ were as follows:

$$
\begin{gathered}
\mathrm{R}^{2}=1-\frac{\sum(\hat{\mathrm{y}}-\mathrm{y})^{2}}{\sum \mathrm{y}^{2}} \\
R M S E=\sqrt{\frac{\sum(\hat{y}-y)^{2}}{n}}
\end{gathered}
$$

where $y$ and $\hat{y}$ represent the observed and remotely-derived GPP, respectively; $n$ is the number of observations (eight-day periods). The best products generally had the highest $\mathrm{R}^{2}$ and the lowest RMSE. All statistical analyses were carried out using the OriginPro software (OriginLab, OriginPro 8.5, Northampton, MA, USA).

\section{Results}

\subsection{Dynamics of GPP, $R_{e}$, and NEE in Dryland Ecosystems}

Firstly, the seasonal dynamics of carbon fluxes (GPP, $R_{e}$, and NEE) are shown in Figure 2. As illustrated in Figure 2, the GPP, $R_{e}$, and NEE of all flux sites showed clear seasonal patterns 
from 2014 to 2016. Particularly, the GPP and $R_{e}$ exhibited consistent trends. During the dormant seasons, the vegetation GPP was nearly zero because photosynthesis stopped. With the increase of temperature during springtime, the GPP and $R_{e}$ increased gradually and reached a peak in July or August. Inversely, the NEE had deep valleys in the growing seasons. It decreased gradually after approximately 18th week of year (WOY 18), to the valley around in July or August, and then gradually increased. In addition, the S_Dm site had the highest GPP at the peak period among all sites. Although consistent seasonal dynamics exist, different ecosystems still had their own characteristics, especially in forest ecosystems (the S_Sdq and S_Hhl sites). The time when GPP began to grow rapidly was earlier at S_Hhl than the rest of the other sites, and the period of carbon sequestration was the longest in every year among all ecosystems. In the S_Sdq site, we found that the peak periods came later year after year from 2014 to 2016.
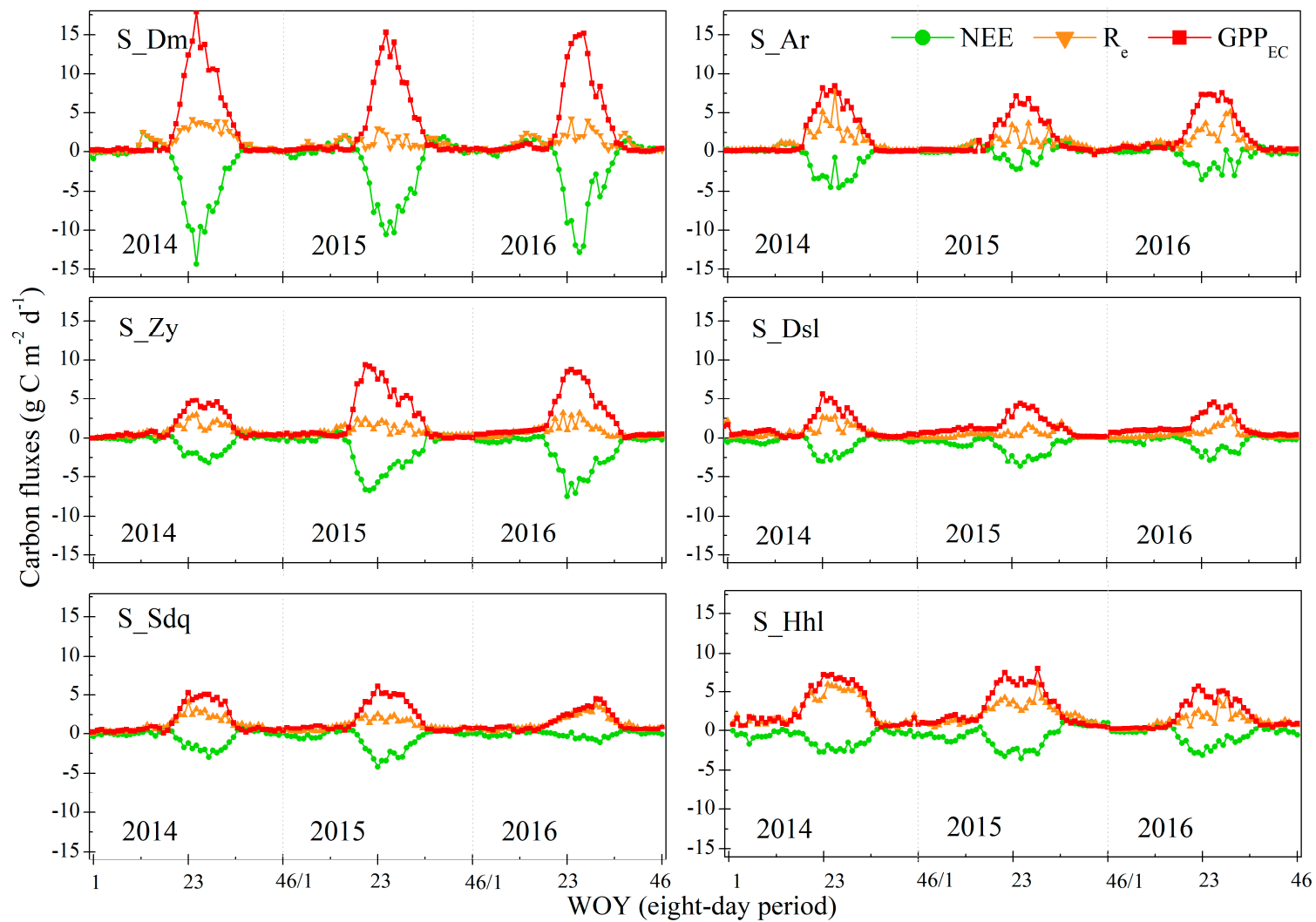

Figure 2. Seasonal variations in carbon fluxes (GPP, $R_{e}$, and NEE) at the typical flux sites between 2014 and 2016 at the eight-day period. WOY means week of year.

To analyze the differences in carbon fluxes between different ecosystems, we conducted a statistical analysis of carbon fluxes (GPP, $R_{e}$, and NEE) from 2014 to 2016. The annual mean carbon fluxes of different ecosystems were statistically calculated, presented in Table 2. Overall, the average annual GPP in all flux sites was greater than the values of $R_{e}$, and according to the NEE annual mean value, it implied that all ecosystems also behaved as carbon sinks. In particular, the S_Dm site had the largest annual mean GPP and NEE, which was near double the GPP and NEE values of other ecosystems. Furthermore, the lowest annual mean GPP value appeared in the S_Dsl site, in which the annual mean $R_{e}$ value was also the lowest, reaching up to $208 \pm 49 \mathrm{~g} \mathrm{C} \mathrm{m}^{-2} \mathrm{y}^{-1}$. However, although both the annual GPP and $R_{e}$ in the S_Dsl site were far lower than those in the S_Ar site, and there was no obvious difference in the annual mean NEE between the two sites. The largest annual mean NEE was found at the S_Sdq site, and it implied that the lowest carbon sequestration was there, about $208 \pm 56 \mathrm{~g} \mathrm{C} \mathrm{m}^{-2} \mathrm{y}^{-1}$. 
Table 2. Annual mean GPP, $R_{e}$, NEE, and the corresponding standard deviations of different ecosystems based on the six flux sites between 2014 and 2016.

\begin{tabular}{ccccc}
\hline \multirow{2}{*}{ Sites } & \multirow{2}{*}{ Vegetation Type } & GPP & $\boldsymbol{R}_{\boldsymbol{e}}$ & NEE \\
\cline { 3 - 4 } & & \multicolumn{3}{c}{$\mathbf{g ~ C ~ m ~}^{\mathbf{- 2}} \mathbf{~ y}^{\mathbf{- 1}}$} \\
\hline S_Dm & Maize cropland & $1183 \pm 39$ & $454 \pm 79$ & $-728 \pm 41$ \\
S_Ar & Alpine meadow & $742 \pm 74$ & $421 \pm 60$ & $-321 \pm 56$ \\
S_Zy & Wetland & $793 \pm 228$ & $324 \pm 16$ & $-469 \pm 234$ \\
S_Dsl & Swamp meadow & $528 \pm 27.33$ & $208 \pm 49$ & $-320 \pm 74$ \\
S_Sdq & Tamarix & $665 \pm 59$ & $456 \pm 55$ & $-208 \pm 56$ \\
S_Hhl & Populus euphratica and Tamarix & $954 \pm 205$ & $728 \pm 239$ & $-227 \pm 95$ \\
\hline
\end{tabular}

\subsection{Performance of Satellite-Based Seasonal GPP}

In this study, three fundamental methods contributing to the analysis of the differences in the seasonal performances of the BESS, MODIS, and GOSIF GPP products were carried out. It is worth noting that the BESS and MODIS GPP extracted based on the S_Sd site locations were both invalid data. Firstly, based on the EC-based observations GPP (GPP $\mathrm{EC}_{\mathrm{EC}}$, we assessed the performance across seasonal courses (Figure 3 ) and the regression relations of the BESS, MODIS, and GOSIF GPP (GPP BESS, $_{\text {, }}$ $\mathrm{GPP}_{\mathrm{MOD}}$, and GPP $\mathrm{SIF}$ ) (Figure 4) at all ecosystems during 2014 and 2015. From Figure 3, we can find that the performances of the three GPP products varied dramatically with different ecosystems. On the whole, the seasonal variation of the three GPP products was the most consistent with the flux site GPP $\mathrm{EC}_{\mathrm{C}}$ of grassland ecosystems (S_Ar and S_Dsl) but remained largely underestimated for the growing seasons at the other EC sites. Furthermore, the three GPP products had well peaks matching at the S_Dm site and a degree of peak delay in both grassland ecosystems (the S_Ar and S_Dsl sites).

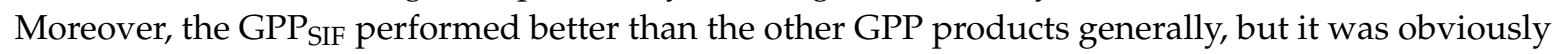
overestimated during the growing season of the S_Ar site.

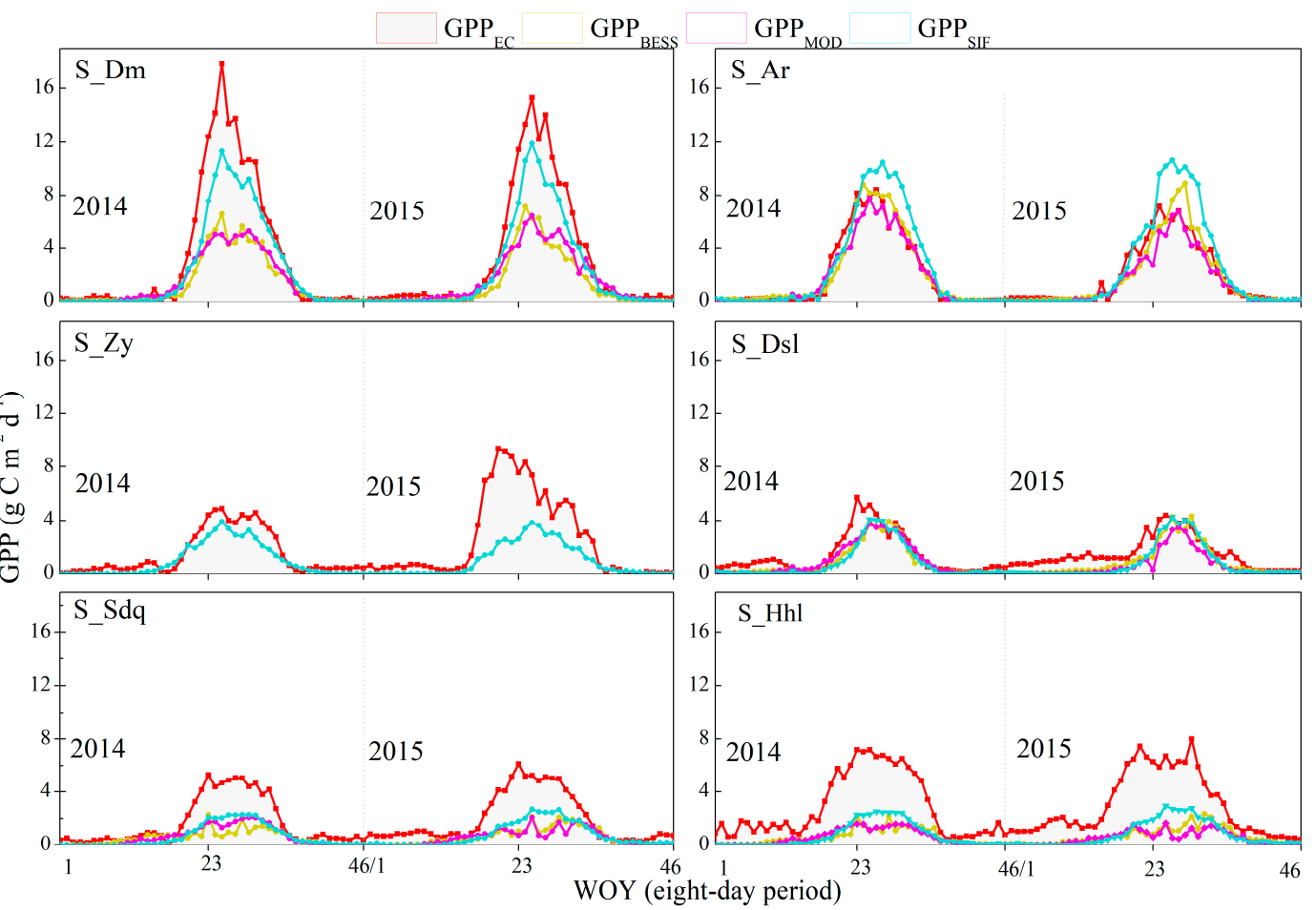

Figure 3. Seasonal dynamics of the GPP from flux measurements $\left(\mathrm{GPP}_{\mathrm{EC}}\right)$ and the estimates from the BESS products $\left(\mathrm{GPP}_{\mathrm{BESS}}\right)$, the MODIS (GPP $\left.\mathrm{MOD}\right)$, and the GOSIF $\left(\mathrm{GPP}_{\mathrm{SIF}}\right)$ at the six flux sites between 2014 and 2015. Note: The values extracted from both MODIS and BESS products were null at the Zhangye wetland site (S_Zy). 


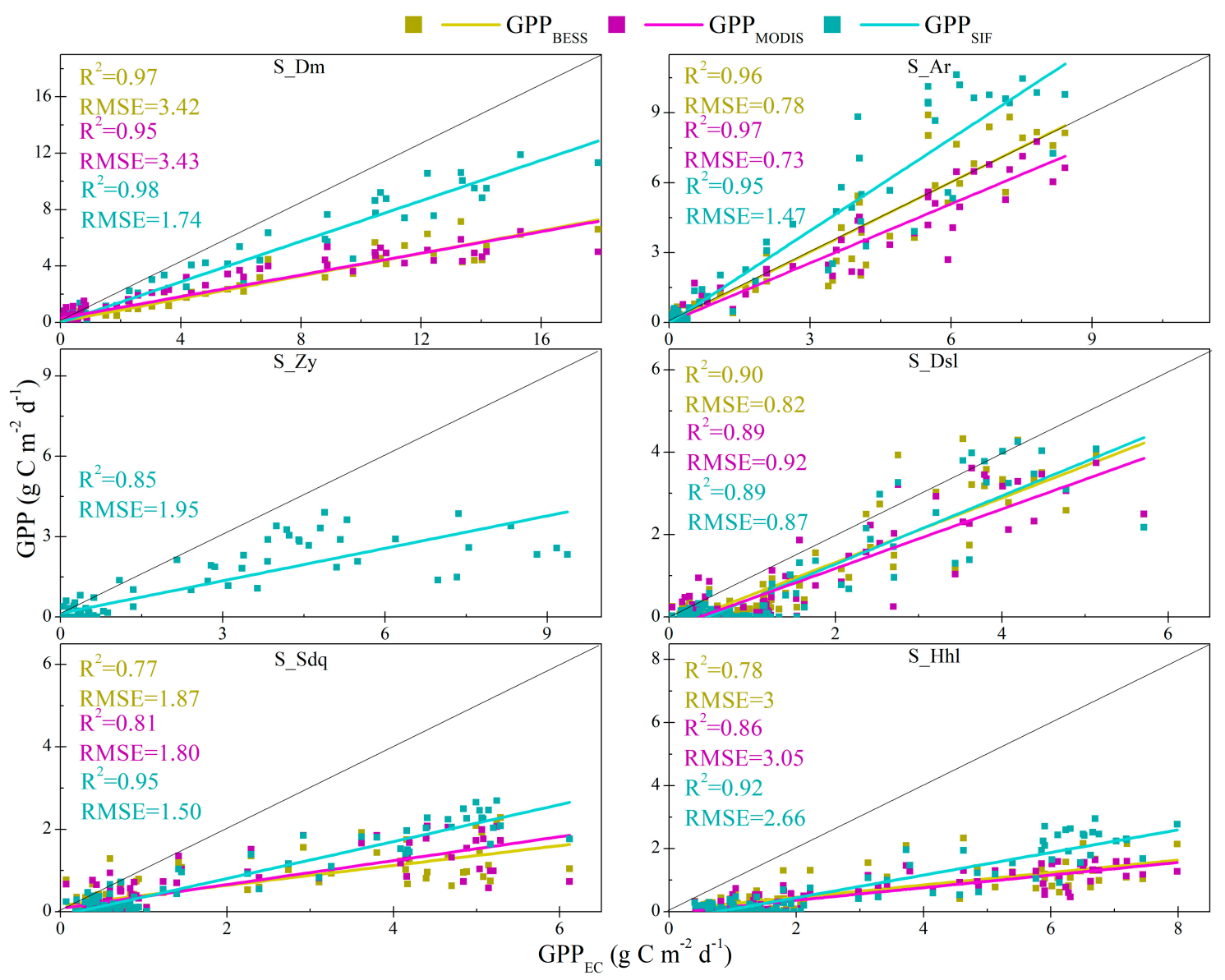

Figure 4. The scatter plots of the ecosystem GPP from flux measurements (GPP $\mathrm{EC}$ ) and GPP $\mathrm{BESS}_{\text {, }}$ $\mathrm{GPP}_{\mathrm{MOD}}$, and $\mathrm{GPP}_{\mathrm{SIF}}$ on the eight-day time scale at the six flux sites. The dotted line and solid line are used to show 1:1 line and linear fit, respectively.

Linear regression analysis was performed to examine the performance of the BESS, MODIS, and GOSIF GPP products on an eight-day period at the five flux sites between 2014 and 2015. As the values of both GPP $\mathrm{BESS}_{\mathrm{B}}$ and GPP $\mathrm{MOD}$ were null at the S_Zy site, the performance of these two products could not be further analyzed. As shown in Figure 4, different GPP products varied with different ecosystems. Overall, the three GPP products' performance was underestimated or overestimated in all EC sites and the GPP SIF $_{\text {performed better than the other GPP products. Especially, the GPP }}$ had the highest consistency with GPP $\mathrm{EC}_{\mathrm{EC}}$ at the S_Dm, the S_Sdq, and the S_Hhl sites, with $\mathrm{R}^{2}$ values ranging from 0.92 to 0.98 and RMSE from 1.5 to $2.66 \mathrm{~g} \mathrm{C} \mathrm{m}^{-2} \mathrm{~d}^{-1}$. However, the $\operatorname{GPP}_{\text {SIF }}\left(\mathrm{R}^{2}=0.95\right.$, RMSE $=1.47 \mathrm{~g} \mathrm{C} \mathrm{m}^{-2} \mathrm{~d}^{-1}$ ) was obviously overestimated at the S_Ar site, having no superiority over the GPP ${ }_{\mathrm{BESS}}$ and GPP $\mathrm{MOD}_{\mathrm{MOD}}$. At the S_Ar and S_Dsl, The GPP $\mathrm{BESS}_{-}$and GPP $\mathrm{MOD}$ were distributed closer to the 1:1 line like the GPP $\mathrm{SIF}_{\mathrm{S}}$, which is consistent with the results of Figure 3.

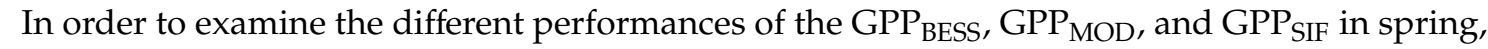
summer, and autumn, we carried out a boxplot analysis, as shown in Figure 5. In terms of grassland ecosystems (S_Ar and S_Dsl), the GPP ${ }_{M O D}$ had better distribution characteristics than the GPP BESS $_{\text {and }}$ $\mathrm{GPP}_{\mathrm{SIF}}$ in summer, while the GPP $\mathrm{BESS}_{\text {was }}$ closer to distribution characteristics of the GPP $\mathrm{EC}_{\mathrm{EC}}$ in spring and autumn. In addition, the GPP SIF performed better only in spring for the S_Ar site. The GPP also had better distribution characteristics than the GPP ${ }_{\mathrm{BESS}}$ and GPP $\mathrm{MOD}$ at the S_Dm site in spring, summer, and autumn. Furthermore, the GPP $\mathrm{BESS}_{1} \mathrm{GPP}_{\mathrm{MOD}}$, and GPP $\mathrm{SIF}$ did not perform well at the S_Sdq and S_Hhl sites. 


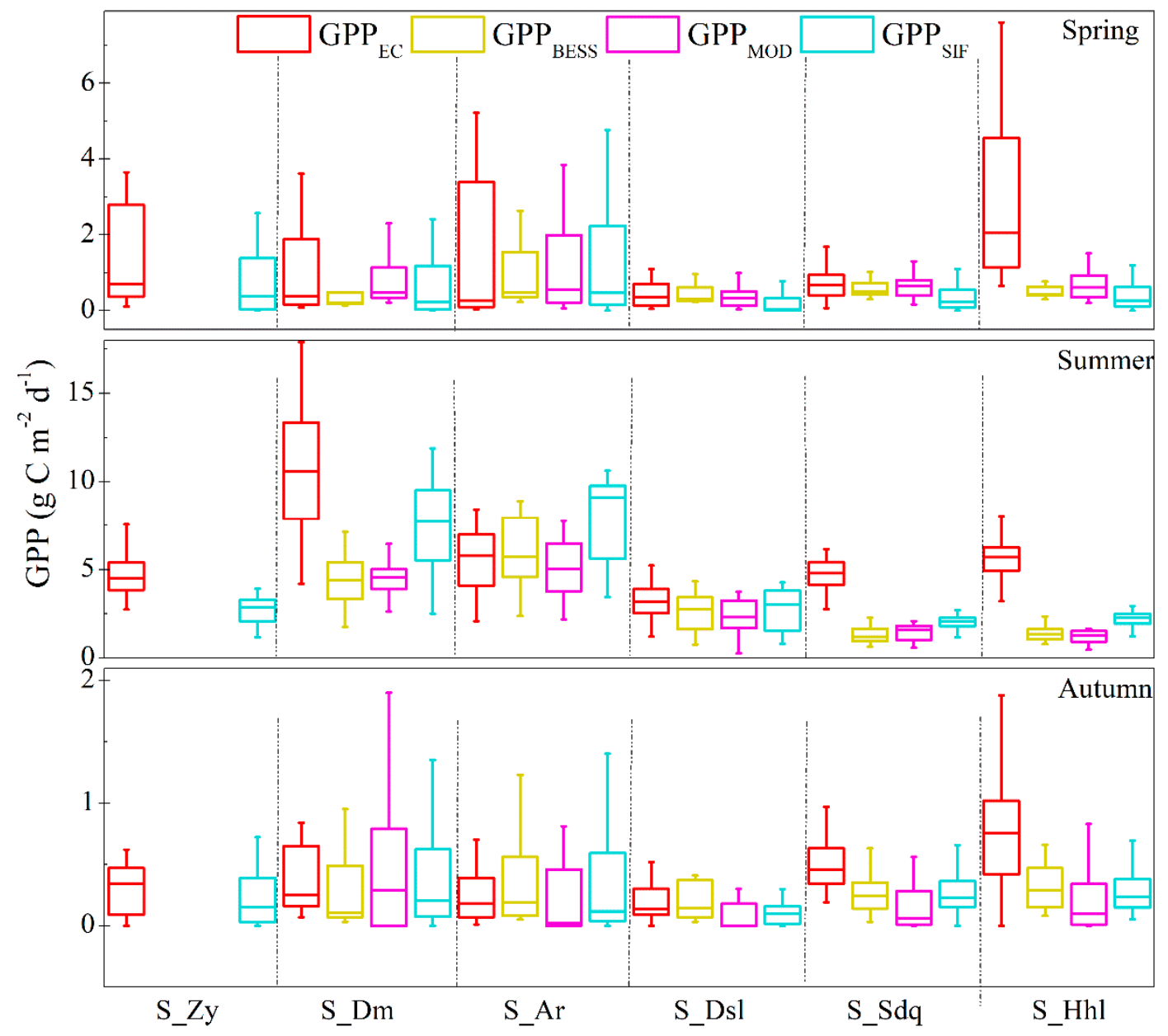

Figure 5. Comparisons of the seasonal patterns of GPP observations $\left(\mathrm{GPP}_{\mathrm{EC}}\right)$ and the remotely-derived products $\left(\mathrm{GPP}_{\mathrm{BESS}}, \mathrm{GPP}_{\mathrm{MOD}}\right.$, and $\left.\mathrm{GPP}_{\mathrm{SIF}}\right)$ at the six flux sites during the periods of spring, summer, autumn, and winter, respectively. The box range and whisker range were $25 \%-75 \%$ and $10 \%-90 \%$, respectively.

\subsection{Annual Mean Patterns of Satellite-Based GPP}

The annual mean GPP from flux measurements (GPP $\left.\mathrm{EC}_{\mathrm{EC}}\right)$, BESS (GPP $\left.\mathrm{BESS}_{\mathrm{B}}\right)$, the MODIS (GPP $\left.\mathrm{MOD}\right)$,

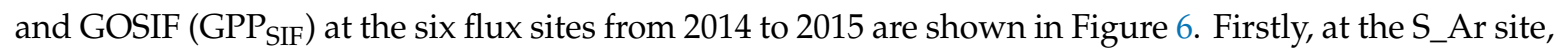

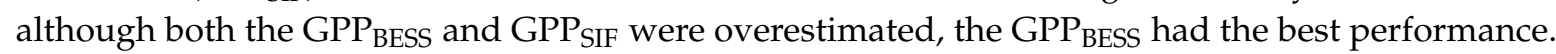
Furthermore, the three GPP products were underestimated in varying degrees at other EC sites. For instance, at the S_Sdq and S_Hhl sites, the three GPPs were severely underestimated by more than half. Similarly, the GPP ${ }_{\mathrm{BESS}}$ and GPP $\mathrm{MOD}$ were only approximately half of the GPP $\mathrm{EC}_{\mathrm{EC}}$ at the S_Dm site. Finally, the GPP $\mathrm{SIF}$ had an obvious advantage at the S_Dm site among the three GPP products. 


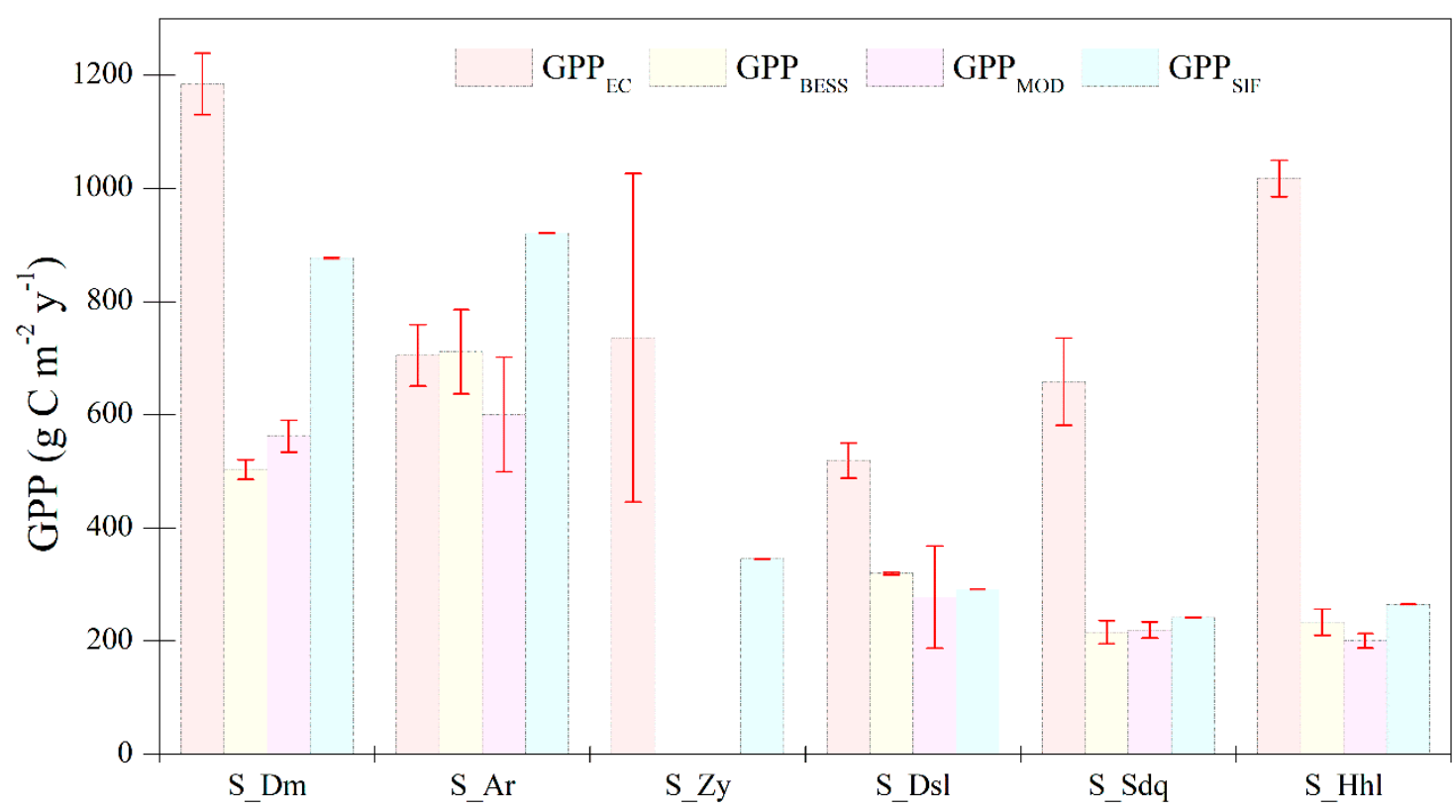

Figure 6. Comparisons of annual mean GPP observations $\left(\mathrm{GPP}_{\mathrm{EC}}\right)$ and the remotely-derived products $\left(\mathrm{GPP}_{\mathrm{BESS}}, \mathrm{GPP}_{\mathrm{MOD}}\right.$, and GPP $\left.\mathrm{SIF}\right)$ at the six flux sites between 2014 and 2015. Note: The values of both $\mathrm{GPP}_{\mathrm{MOD}}$ and GPP $\mathrm{BESS}_{\mathrm{B}}$ were null at the $\mathrm{S} \_\mathrm{Zy}$.

\section{Discussion}

\subsection{Uncertainty in EC-Based GPP}

Compromised due to instrument malfunctions, inadequate power supply, and bad weather, certain carbon fluxes and meteorological data can have poor quality and are even lost, which is inevitable. In the above cases, the data with an occasional segment missing or quality problems have been dealt with by the methods of gap-filling using the R package. However, for data gaps or quality problems of more than one month, we gap-filled with multi-year mean imputation, which was mainly used at the S_Sdq site in 2016. To some extent, it covered up the difference left by the specific environment, which showed some uncertainties. Besides, previous work has reported the overestimation of plant photosynthetic uptake when using the integrated open-path eddy covariance system [42]. Despite uncertainties, the six flux sites selected in this study represent the most typical ASA ecosystems in western China. The results obtained in this study also clearly reveal the quadratic functional characteristics of carbon fluxes (GPP, $R_{e}$, and NEE) concerning the seasonal dynamics in these ecosystems. Further, the results suggest that the cropland ecosystems achieved the highest annual GPP values of $1182.68 \pm 38.62 \mathrm{~g} \mathrm{C} \mathrm{m}^{-2} \mathrm{y}^{-1}$ among all ASA ecosystems, which was consistent with the result of $\mathrm{Gu}$ [15]. On the annual scale, the values of GPP $\mathrm{EC}_{\mathrm{C}}$ at the S_Ar and S_Dsl sites were about $741 \mathrm{~g} \mathrm{C} \mathrm{m}^{-2} \mathrm{y}^{-1}$ and $528 \mathrm{~g} \mathrm{C} \mathrm{m}^{-2} \mathrm{y}^{-1}$. The heavy precipitation events (over $10 \mathrm{~mm} \mathrm{day}^{-1}$ ) as well as precipitation intervals have been reported to impact GPP in the temperate steppe or the alpine meadow ecosystems [43]. Compared with the S_Dsl site, we found that the S_Ar had more frequent precipitation events (an average of 13 days during the growing season of 2014-2015), and annual average precipitation was about $460 \pm 63 \mathrm{~mm}$, which was likely to favor the higher GPP value of the S-Ar site. For semi-arid grasslands in the western United States, Álvarez-Taboada [44] examined three grassland ecosystems under water-limited conditions and found that the EC-based GPPs were about $500 \mathrm{~g} \mathrm{C} \mathrm{m}^{-2} \mathrm{y}^{-1}$. Especially at the Vaira Ranch-Ione site with annual cumulative precipitation of approximately $630 \mathrm{~mm}$, the mean GPP from 2004 to 2006 was approximately $822 \mathrm{~g} \mathrm{C} \mathrm{m}^{-2} \mathrm{y}^{-1}$. Therefore, the carbon fixation in the arid and semi-arid ecosystems was strongly constrained by water availability and fluctuated annually. 


\subsection{Error Sources of Remotely-Derived Products}

This study found that both the MODIS and BESS GPP performed with good accuracy for grasslands, which was consistent with previous studies $[29,45]$, but larger uncertainties existed in other ecosystems. Regardless of the algorithm error, the precision of the model parameters used for the estimation plays an indispensable role in the accuracy of GPP estimation. For the input parameters of the MODIS GPP algorithm, we can take knowledge from the MOD17 user guide [38], while for the model parameters of the BESS GPP, the description is very clear in the research of Jiang and Ryu [29]. The BESS model contains the six key modules algorithm [17], and most of its input parameters come from the MODIS products whose resolution difference is large enough to make uncertainty inevitable in the process of the resolution consistency. For the GOSIF GPP, the GOSIF data set, the key part of the input data was affected by MERRA-2 with coarse spatial resolution [41]. Therefore, these products had their own errors.

In this study, we found that these BESS, MODIS, and GOSIF GPP products largely underestimated the GPP during the growing period, except the S_Ar site. This can be partly explained by the open-path EC-based flux measurements. Such systems would inevitably lead to the overestimation of the GPP of terrestrial ecosystems because of the limitation of technical means. However, the GOSIF GPP had obvious advantages in seasonal and interannual dynamics, which can be ascribed to the universal GOSIF-GPP relationship and negligible impact of land covers [41]. Through a thorough analysis of the performances of the MODIS and BESS GPP, we found that both the BESS and MODIS GPP underestimated the GPP data by more than half at S_Hhl (Figures 3 and 6). The reason can be largely explained by the fact that both the BESS and MODIS GPP products used the same land cover product (MCD12Q1) [29,46], which had significant classification uncertainty. Different judgments of land cover resulted in inaccurate LUEmax and affected the estimation results. Figure 7 showed that the S_Hhl and S_Sdq sites were located on grasslands surface, but not on Populus euphratica and Tamarix spp. For the MODIS GPP product, LUEmax, Tmin, and VPD of grasslands are much lower than those of forest land, which is another important reason for underestimation. Zhao [47] found that the Tmin and VPD from the GMAO were generally underestimated. Furthermore, the LUEmax value in MODIS GPP depends on the simple look-up table approach. Among the same vegetation types, the LUEmax value was also generally underestimated [48]. After Wang [28] optimized the LUEmax using the site-observed GPP, the performance of the MODIS GPP had obvious improvement. The footprints of these flux sites can reach several hundred meters around the tower. However, owing to the spatial heterogeneity, its effect on the remote sensing-based GPP products cannot be neglected, which would lead to inconsistency between the site-level measurement and satellite-based product. In addition, soil moisture has been indicated as a major factor limiting the GPP in the water-constrained ecosystems [15,49]. However, the BESS GPP assumed that the water stress is embedded in the variability of leaf area index, which lacked an accurate proxy for soil moisture dynamics [50].

The BESS and MODIS GPP applied different types of models, which made it hard to compare from the model structure. However, the most important difference is that the BESS model distinguished the difference between $C_{3}$ and $C_{4}$ plants while MODIS GPP did not. The cropland ecosystems mainly represent rice at MCD12Q1 land cover products. Wang [51] also found that the GPP of maize was obviously higher than the other $C_{3}$ crops. Rice at the $S_{-}$Dm is a $C_{3}$ plant different from $C_{4}$ plants (maize), which is the main reason for the underestimation of MODIS GPP. Although considering the differences in ecophysiological characteristics of $C_{3}$ and $C_{4}$ species, the BESS GPP underestimated by about $50 \%$ of actual measurement (Figures 3 and 6 ). This is because the BESS GPP depended on the relative proportion of two species on a pixel, and $C_{4}$ plants account for only less than 0.205 at the S_Dm [52]. 


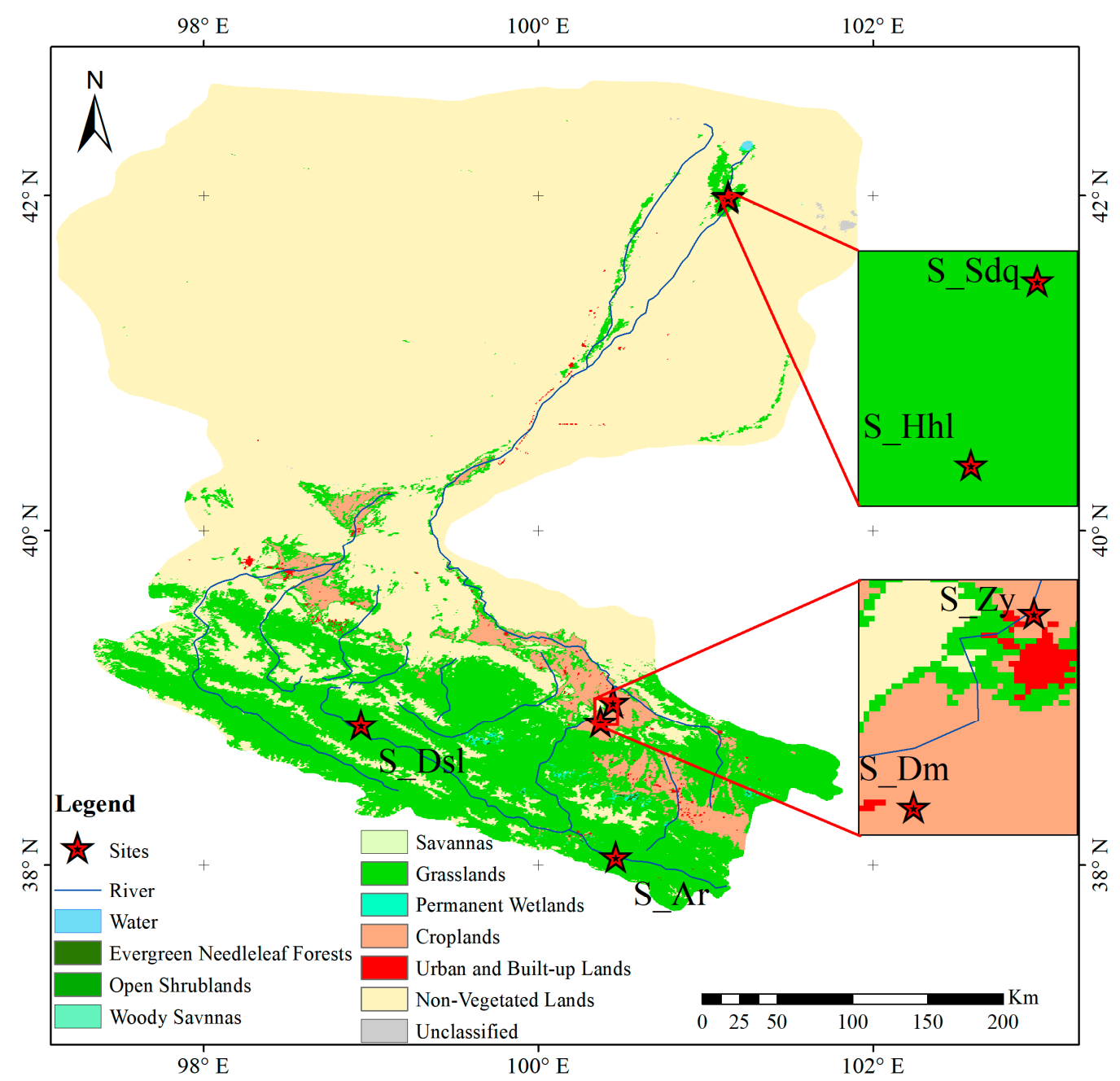

Figure 7. MCD12Q1 land cover types at each flux site in 2014. The data is from https://lpdaac.usgs.gov/.

Although the GOSIF GPP had also underestimated at the S_Dm, S_Hhl, and S_Sdq sites, it had the best performed among the three GPP products (Figures 3 and 4). Reasons abound, for instance, $\mathrm{Li}$ and Xiao [41] found that the impact of land cover on product accuracy is much smaller than that of training samples. Therefore, the land cover maps were not taken into account when the GOSIF products are produced. Similarly, Li and Xiao [24] used a nearly universal rather than biome-specific SIF-GPP relationship to get the GOSIF GPP product. In a nutshell, the GOSIF GPP reduced the impact of land cover classification uncertainty to some extent.

\subsection{Effect on Global Climate Change}

With changing climate, the influence of carbon sequestration in semi-arid biomes may be of more importance for global carbon sink than in tropical rainforests inter-annually ( $<10$ years) in the future [53]. In this study, we found that carbon fluxes varied in different years and different dryland ecosystems. On one hand, it suggested that with restrictions on water resources, ASA ecosystems remained a large carbon sink. On the other hand, there was much uncertainty for carbon sequestration across ASA regions. Meanwhile, large areas of grassland and woodland in Australia has been invaded by shrubs, which lead to a serious decline in pastoral productivity [54]. In this study, we found that the grassland ecosystem is the highest carbon-sequestered vegetation other than farmland. $\mathrm{Gu}$ [15] found that soil moisture showed a large positive correlation with the GPP in ASA regions in China. Soil moisture content can reflect soil texture to some extent, which means that grassland has excellent water conservation function and can alleviate the continuous expansion of drought. 
Therefore, accurately estimating the GPP provided an important scientific method and data support for quantifying carbon sink and source in ASA ecosystems to contribute to the development of regional carbon management planning and decision-making.

\section{Conclusions}

Based on six flux sites in northwest China, this study examined the differences in seasonal and interannual carbon fluxes across the typical ASA ecosystems in northwest China. The results indicate that the carbon fluxes of these dryland ecosystems have clear seasonal dynamics and vary inter-annually, and all ecosystems function as carbon sinks on the annual time scale. Moreover, we also assessed the performance of these remotely-derived BESS, MODIS, and GOSIF GPP products, and got some evidence. Except for at the S_Ar and S_Dsl sites, some distinct advantages of the GOSIF GPP were picked up, not only in the seasonal dynamic but also in annual mean difference. The universal GOSIF-GPP relationship and less impact of land cover helped the GOSIF GPP algorithm. Furthermore, both the MODIS and BESS products largely underestimated the GPP during the growing period. Compared with the MODIS GPP, the BESS GPP was more reliable for swamp meadow and alpine grassland ecosystems. However, large uncertainties in the BEES, MODIS, and GOSIF GPP products remain. Therefore, precise input parameters should be used to improve the products, such as accurate land cover types and LUEmax at high spatial resolution. Meanwhile, the MODIS GPP will be greatly improved by considering the differences in sun and shade leaves, and $C_{3} / C_{4}$ plants. The accuracy of the BESS GPP can be also improved by adding the soil moisture effect in water-limited areas, and the accuracy of the GOSIF GPP could be further improved with high-quality meteorological data. All these analyses would be helpful for providing reliable GPP products in the ecologically-fragile dryland ecosystems and supporting policies for sustainable development.

Author Contributions: Conceptualization, Q.G. and X.T.; methodology, Q.G. and X.T.; validation, Q.G.; formal analysis, Q.G. and M.W.; data curation X.W.; writing—review and editing, Q.G, H.Z., M.M., and L.Y. All authors have read and agreed to the published version of the manuscript.

Funding: This study was jointly supported by the Fundamental Research Funds for the Central Universities (XDJK2020C015); Foundation of Key Laboratory of Geospatial Technology for the Middle and Lower Yellow River Regions (GTYR201908); and Key Laboratory of Watershed Geographic Sciences, Nanjing Institute of Geography and Limnology, Chinese Academy of Sciences (WSGS2020007).

Acknowledgments: This work used flux data acquired from the Heihe Watershed Allied Telemetry Experimental Research (Hi-WATER). All scientists and technicians maintaining the flux site management, data collection, and long-term observations are greatly appreciated. We also thank the principal contributors of the MODIS products, the Distributed Active Archive Center of the Oak Ridge National Laboratory and the Earth Observing System Data, and the BESS products from the Environmental Ecology Lab at Seoul National University.

Conflicts of Interest: No potential conflict of interest was reported by the authors.

\section{References}

1. Haverd, V.; Ahlström, A.; Smith, B.; Canadell, J.G. Carbon cycle responses of semi-arid ecosystems to positive asymmetry in rainfall. Glob. Chang. Biol. 2017, 23, 793-800. [CrossRef]

2. Gilbert, J.M.; Maxwell, R.M. Contrasting warming and drought in snowmelt-dominated agricultural basins: Revealing the role of elevation gradients in regional response to temperature change. Environ. Res. Lett. 2018, 13, 074023. [CrossRef]

3. Trenberth, K.E.; Dai, A.; Van Der Schrier, G.; Jones, P.D.; Barichivich, J.; Briffa, K.R.; Sheffield, J. Global warming and changes in drought. Nat. Clim. Chang. 2014, 4, 17-22. [CrossRef]

4. Koutroulis, A.G. Dryland changes under different levels of global warming. Sci. Total Environ. 2019, 655, 482-511. [CrossRef]

5. Dregne, H.E. Land degradation in the drylands. Arid Land Res. Manag. 2002, 16, 99-132. [CrossRef]

6. Zika, M.; Erb, K.-H. The global loss of net primary production resulting from human-induced soil degradation in drylands. Ecol. Econ. 2009, 69, 310-318. [CrossRef] 
7. Poulter, B.; Frank, D.; Ciais, P.; Myneni, R.B.; Andela, N.; Bi, J.; Broquet, G.; Canadell, J.G.; Chevallier, F.; Liu, Y.Y. Contribution of semi-arid ecosystems to interannual variability of the global carbon cycle. Nature 2014, 509, 600-603. [CrossRef] [PubMed]

8. Biederman, J.A.; Scott, R.L.; Bell, T.W.; Bowling, D.R.; Dore, S.; Garatuza-Payan, J.; Kolb, T.E.; Krishnan, P.; Krofcheck, D.J.; Litvak, M.E. $\mathrm{CO}_{2}$ exchange and evapotranspiration across dryland ecosystems of southwestern North America. Glob. Chang. Biol. 2017, 23, 4204-4221. [CrossRef]

9. Chevallier, F.; Ciais, P.; Conway, T.; Aalto, T.; Anderson, B.; Bousquet, P.; Brunke, E.; Ciattaglia, L.; Esaki, Y.; Fröhlich, M. $\mathrm{CO}_{2}$ surface fluxes at grid point scale estimated from a global 21 year reanalysis of atmospheric measurements. J. Geophys. Res. Atmos. 2010, 115. [CrossRef]

10. Sitch, S.; Smith, B.; Prentice, I.C.; Arneth, A.; Bondeau, A.; Cramer, W.; Kaplan, J.O.; Levis, S.; Lucht, W.; Sykes, M.T. Evaluation of ecosystem dynamics, plant geography and terrestrial carbon cycling in the LPJ dynamic global vegetation model. Glob. Chang. Biol. 2003, 9, 161-185. [CrossRef]

11. Baldocchi, D. Measuring fluxes of trace gases and energy between ecosystems and the atmosphere-the state and future of the eddy covariance method. Glob. Chang. Biol. 2014, 20, 3600-3609. [CrossRef] [PubMed]

12. Braswell, B.H.; Sacks, W.J.; Linder, E.; Schimel, D.S. Estimating diurnal to annual ecosystem parameters by synthesis of a carbon flux model with eddy covariance net ecosystem exchange observations. Glob. Chang. Biol. 2005, 11, 335-355. [CrossRef]

13. Grünzweig, J.; Lin, T.; Rotenberg, E.; Schwartz, A.; Yakir, D. Carbon sequestration in arid-land forest. Glob. Chang. Biol. 2003, 9, 791-799. [CrossRef]

14. Kurc, S.A.; Small, E.E. Soil moisture variations and ecosystem-scale fluxes of water and carbon in semiarid grassland and shrubland. Water Resour. Res. 2007, 43. [CrossRef]

15. Gu, Q.; Wei, J.; Luo, S.; Ma, M.; Tang, X. Potential and environmental control of carbon sequestration in major ecosystems across arid and semi-arid regions in China. Sci. Total Environ. 2018, 645, 796-805. [CrossRef]

16. Gilabert, M.A.; Sánchez-Ruiz, S.; Moreno, Á. Annual gross primary production from vegetation indices: A theoretically sound approach. Remote Sens. 2017, 9, 193. [CrossRef]

17. Ryu, Y.; Baldocchi, D.D.; Kobayashi, H.; van Ingen, C.; Li, J.; Black, T.A.; Beringer, J.; Van Gorsel, E.; Knohl, A.; Law, B.E. Integration of MODIS land and atmosphere products with a coupled-process model to estimate gross primary productivity and evapotranspiration from $1 \mathrm{~km}$ to global scales. Glob. Biogeochem. Cycles 2011, 25. [CrossRef]

18. Monteith, J.L. Climate and the efficiency of crop production in Britain. Philos. Trans. R. Soc. Lond. B 1977, 281, 277-294.

19. Baldocchi, D. Measuring and modelling carbon dioxide and water vapour exchange over a temperate broad-leaved forest during the 1995 summer drought. Plantcell Environ. 1997, 20, 1108-1122. [CrossRef]

20. Alton, P.; Ellis, R.; Los, S.; North, P. Improved global simulations of gross primary product based on a separate and explicit treatment of diffuse and direct sunlight. J. Geophys. Res.-Atmos. 2007, 112. [CrossRef]

21. Wang, Y.-P.; Leuning, R. A two-leaf model for canopy conductance, photosynthesis and partitioning of available energy I:: Model description and comparison with a multi-layered model. Agric. For. Meteorol. 1998, 91, 89-111. [CrossRef]

22. Chen, J.; Liu, J.; Cihlar, J.; Goulden, M. Daily canopy photosynthesis model through temporal and spatial scaling for Remote Sens. applications. Ecol. Model. 1999, 124, 99-119. [CrossRef]

23. Shao, C.; Chen, J.; Li, L. Grazing alters the biophysical regulation of carbon fluxes in a desert steppe. Environ. Res. Lett. 2013, 8, 025012. [CrossRef]

24. Li, X.; Xiao, J. Mapping Photosynthesis Solely from Solar-Induced Chlorophyll Fluorescence: A Global, Fine-Resolution Dataset of Gross Primary Production Derived from OCO-2. Remote Sens. 2019, 11, 2563. [CrossRef]

25. Propastin, P.; Ibrom, A.; Knohl, A.; Erasmi, S. Effects of canopy photosynthesis saturation on the estimation of gross primary productivity from MODIS data in a tropical forest. Remote Sens. Environ. 2012, 121, 252-260. [CrossRef]

26. Tramontana, G.; Ichii, K.; Camps-Valls, G.; Tomelleri, E.; Papale, D. Uncertainty analysis of gross primary production upscaling using Random Forests, Remote Sens. and eddy covariance data. Remote Sens. Environ. 2015, 168, 360-373. [CrossRef] 
27. Zhang, J.; Liu, C.; Hao, H.; Sun, L.; Qiao, Q.; Wang, H.; Ning, Y. Spatial-temporal change of carbon storage and carbon sink of grassland ecosystem in the Three-River Headwaters Region based on MODIS GPP/NPP data. Ecol. Environ. Sci. 2015, 24, 8-13.

28. Wang, H.; Li, X.; Ma, M.; Geng, L. Improving estimation of Gross primary production in dryland ecosystems by a model-data fusion approach. Remote Sens. 2019, 11, 225. [CrossRef]

29. Jiang, C.; Ryu, Y. Multi-scale evaluation of global gross primary productivity and evapotranspiration products derived from Breathing Earth System Simulator (BESS). Remote Sens. Environ. 2016, 186, 528-547. [CrossRef]

30. Li, X.; Liu, S.; Xiao, Q.; Ma, M.; Jin, R.; Che, T.; Wang, W.; Hu, X.; Xu, Z.; Wen, J. A multiscale dataset for understanding complex eco-hydrological processes in a heterogeneous oasis system. Sci. Data 2017, 4, 170083. [CrossRef]

31. Wu, F.; Bai, Y.; Zhang, Y.; Li, Z. Balancing water demand for the Heihe River Basin in Northwest China. Phys. Chem. Earth Parts A/B/C 2017, 101, 178-184. [CrossRef]

32. Li, X.; Cheng, G.; Liu, S.; Xiao, Q.; Ma, M.; Jin, R.; Che, T.; Liu, Q.; Wang, W.; Qi, Y. Heihe watershed allied telemetry experimental research (HiWATER): Scientific objectives and experimental design. Bull. Am. Meteorol. Soc. 2013, 94, 1145-1160. [CrossRef]

33. Li, X.; Zhao, N.; Jin, R.; Liu, S.; Sun, X.; Wen, X.; Wu, D.; Zhou, Y.; Guo, J.; Chen, S.; et al. Internet of Things to network smart devices for ecosystem monitoring. Sci. Bull. 2019, 64, 1234-1245. [CrossRef]

34. Wang, N.; Jia, L.; Zheng, C.; Menenti, M. Estimation of subpixel snow sublimation from multispectral satellite observations. J. Appl. Remote Sens. 2017, 11, 046017. [CrossRef]

35. Webb, E.K.; Pearman, G.I.; Leuning, R. Correction of flux measurements for density effects due to heat and water vapour transfer. Q. J. R. Meteorol. Soc. 1980, 106, 85-100. [CrossRef]

36. Liu, S.M.; Xu, Z.W.; Wang, W.; Jia, Z.; Zhu, M.; Bai, J.; Wang, J. A comparison of eddy-covariance and large aperture scintillometer measurements with respect to the energy balance closure problem. Hydrol. Earth Syst. Sci. 2011, 15, 1291-1306. [CrossRef]

37. Liu, S.; Li, X.; Xu, Z.; Che, T.; Xiao, Q.; Ma, M.; Liu, Q.; Jin, R.; Guo, J.; Wang, L. The Heihe Integrated Observatory Network: A basin-scale land surface processes observatory in China. Vadose Zone J. 2018, 17, 1-21. [CrossRef]

38. Running, S.W.; Zhao, M. Daily GPP and annual NPP (MOD17A2/A3) products NASA Earth Observing System MODIS land algorithm. MOD17 User's Guide 2015, 2015, 1-28.

39. Running, S.; Mu, Q.; Zhao, M. MOD17A2H MODIS/Terra Gross Primary Productivity 8-Day L4 Global $500 \mathrm{~m}$ SIN Grid V006; NASA EOSDIS Land Processes DAAC: Sioux Falls, SD, USA, 2015.

40. Li, X.; Xiao, J.; He, B.; Altaf Arain, M.; Beringer, J.; Desai, A.R.; Emmel, C.; Hollinger, D.Y.; Krasnova, A.; Mammarella, I.; et al. Solar-induced chlorophyll fluorescence is strongly correlated with terrestrial photosynthesis for a wide variety of biomes: First global analysis based on OCO-2 and flux tower observations. Glob. Chang. Biol. 2018, 24, 3990-4008. [CrossRef]

41. Li, X.; Xiao, J. A Global, 0.05-Degree Product of Solar-Induced Chlorophyll Fluorescence Derived from OCO-2, MODIS, and Reanalysis Data. Remote Sens. 2019, 11, 517. [CrossRef]

42. Wang, W.; Xu, J.; Gao, Y.; Bogoev, I.; Cui, J.; Deng, L.; Hu, C.; Liu, C.; Liu, S.; Shen, J.; et al. Performance Evaluation of an Integrated Open-Path Eddy Covariance System in a Cold Desert Environment. JAtOT 2016, 33, 2385-2399. [CrossRef]

43. Guo, Q.; Hu, Z.; Li, S.; Yu, G.; Sun, X.; Zhang, L.; Mu, S.; Zhu, X.; Wang, Y.; Li, Y. Contrasting responses of gross primary productivity to precipitation events in a water-limited and a temperature-limited grassland ecosystem. Agric. For. Meteorol. 2015, 214, 169-177. [CrossRef]

44. Álvarez-Taboada, F.; Tammadge, D.; Schlerf, M.; Skidmore, A. Assessing MODIS GPP in non-forested biomes in water limited areas using EC tower data. Remote Sens. 2015, 7, 3274-3292. [CrossRef]

45. Liu, Z.; Shao, Q.; Liu, J. The performances of MODIS-GPP and-ET products in China and their sensitivity to input data (FPAR/LAI). Remote Sens. 2015, 7, 135-152. [CrossRef]

46. Wang, H.; Jia, G.; Fu, C.; Feng, J.; Zhao, T.; Ma, Z. Deriving maximal light use efficiency from coordinated flux measurements and satellite data for regional gross primary production modeling. Remote Sens. Environ. 2010, 114, 2248-2258. [CrossRef]

47. Zhao, M.; Running, S.W.; Nemani, R.R. Sensitivity of Moderate Resolution Imaging Spectroradiometer (MODIS) terrestrial primary production to the accuracy of meteorological reanalyses. J. Geophys. Res.-Biogeosci. 2006, 111. [CrossRef] 
48. Running, S.W.; Baldocchi, D.; Turner, D.; Gower, S.T.; Bakwin, P.; Hibbard, K. A global terrestrial monitoring network integrating tower fluxes, flask sampling, ecosystem modeling and EOS satellite data. Remote Sens. Environ. 1999, 70, 108-127. [CrossRef]

49. Scott, R.L.; Hamerlynck, E.P.; Jenerette, G.D.; Moran, M.S.; Barron-Gafford, G.A. Carbon dioxide exchange in a semidesert grassland through drought-induced vegetation change. J. Geophys. Res.-Biogeosci. 2010, 115. [CrossRef]

50. Thomas, C.K.; Law, B.E.; Irvine, J.; Martin, J.G.; Pettijohn, J.C.; Davis, K.J. Seasonal hydrology explains interannual and seasonal variation in carbon and water exchange in a semiarid mature ponderosa pine forest in central Oregon. J. Geophys. Res.-Biogeosci. 2009, 114. [CrossRef]

51. Wang, T.; Tang, X.; Zheng, C.; Gu, Q.; Wei, J.; Ma, M. Differences in ecosystem water-use efficiency among the typical croplands. Agric. Water Manag. 2018, 209, 142-150. [CrossRef]

52. Still, C.J.; Berry, J.A.; Collatz, G.J.; DeFries, R.S. Global distribution of $\mathrm{C}_{3}$ and $\mathrm{C}_{4}$ vegetation: Carbon cycle implications. Glob. Biogeochem. Cycles 2003, 17, 6-1-6-14. [CrossRef]

53. Zhang, X.; Wang, Y.P.; Peng, S.; Rayner, P.J.; Ciais, P.; Silver, J.D.; Piao, S.; Zhu, Z.; Lu, X.; Zheng, X. Dominant regions and drivers of the variability of the global land carbon sink across timescales. Glob. Chang. Biol. 2018, 24, 3954-3968. [CrossRef]

54. Daryanto, S.; Eldridge, D.J.; Throop, H.L. Managing semi-arid woodlands for carbon storage: Grazing and shrub effects on above-and belowground carbon. Agric. Ecosyst. Environ. 2013, 169, 1-11. [CrossRef]

(C) 2020 by the authors. Licensee MDPI, Basel, Switzerland. This article is an open access article distributed under the terms and conditions of the Creative Commons Attribution (CC BY) license (http://creativecommons.org/licenses/by/4.0/). 